\title{
frontón recoletos
}

emplazamiento: Calle Villanueva, Madrid

año: 1935

arquitecto: SECUNDINO ZUAZO

constructor: Huarte

El juego de pelota requiere una gran superficie de juego, rectangular y limitada por un muro de frente, otro lateral y otro de fondo para el rebote de la pelota. Las localidades se sitúan, principalmente, al otro lado de la longitud de la pista de juego.

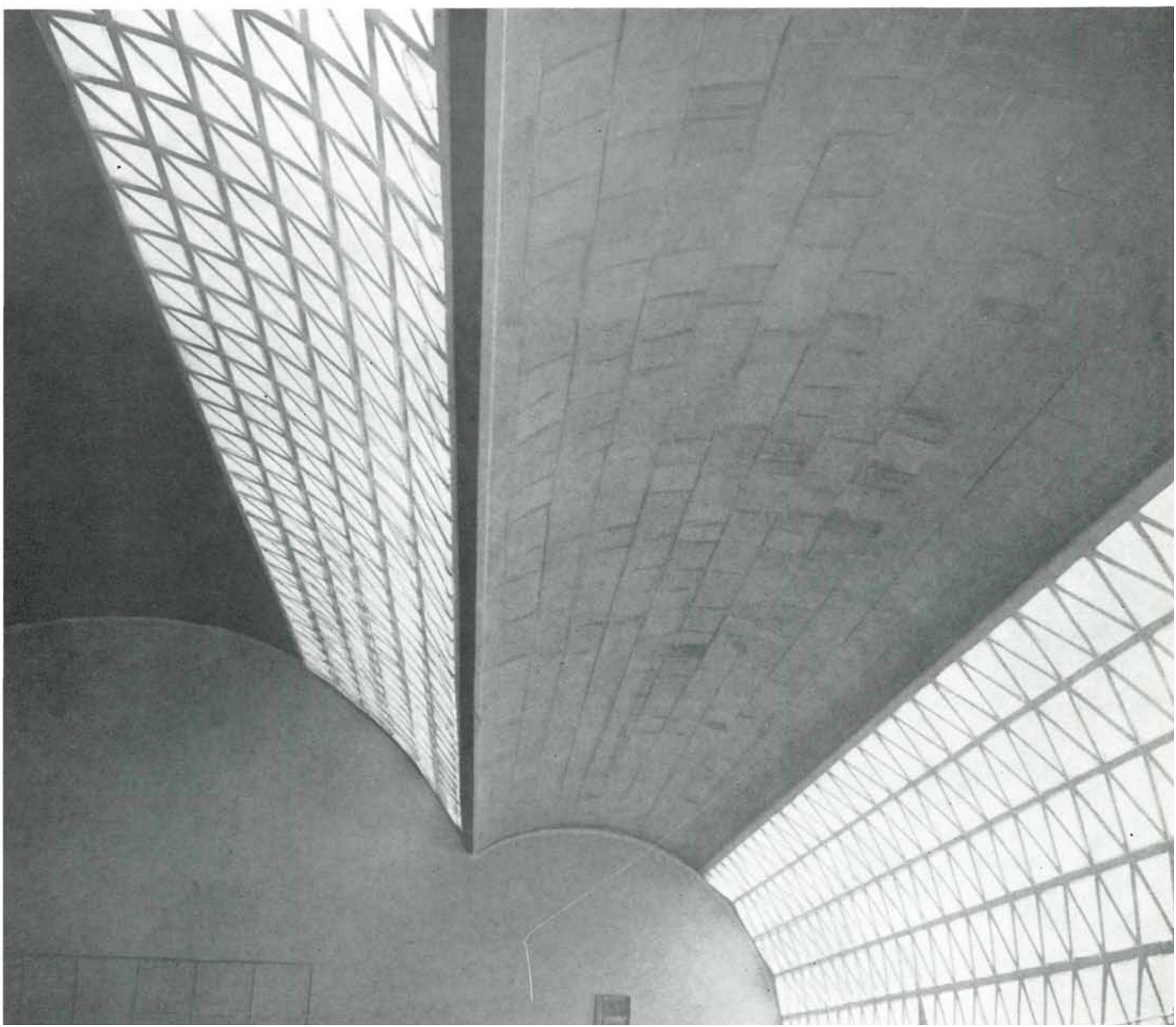




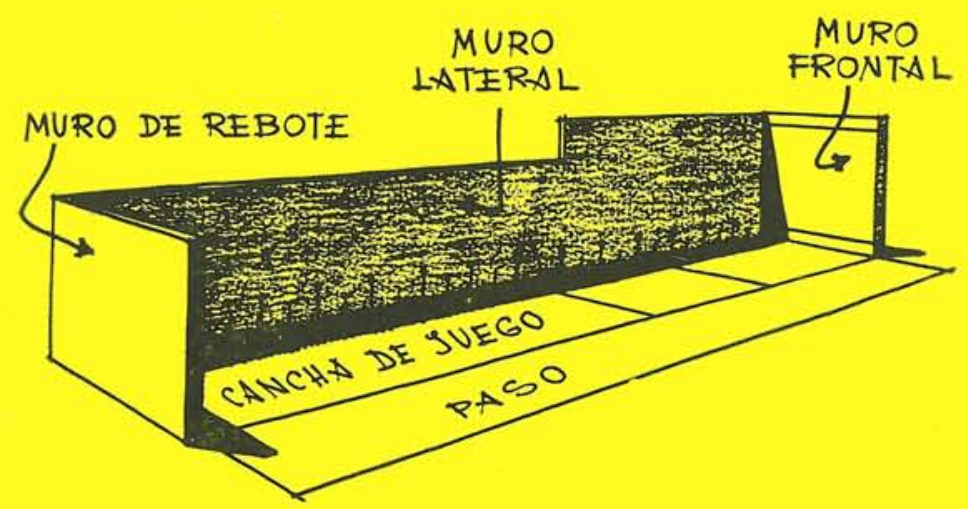

ALTURA MPNIMA

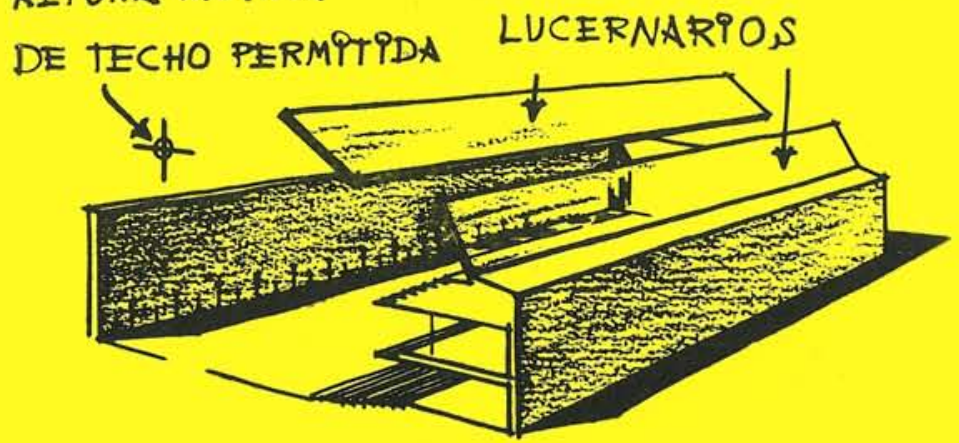

FORMNS TRANSVERSALES
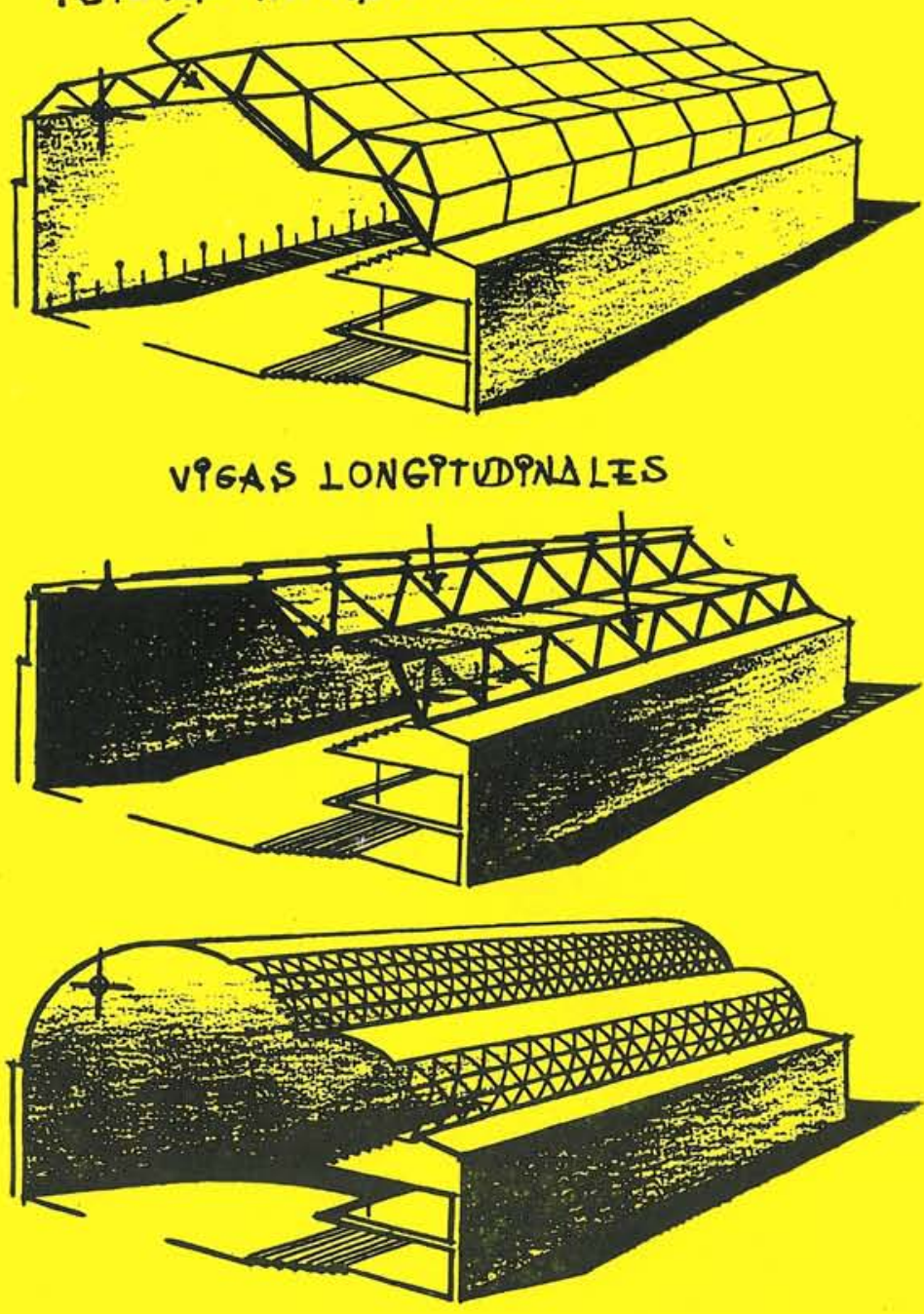

La estructura de las plantas bajas no tiene nada de especial. El graderío alto está sostenido por vigas y ménsulas que apoyan sobre un cargadero de 4,00 metros de altura total y 23 metros de luz. De esas ménsulas cuelgan los tirantes que sostienen el piso de palcos. De este modo queda totalmente libre la zona baja de circulación de la que se pasa al graderío bajo.

Dada la orientación de la sala y la forma asimétrica de la planta, convenía dejar en cubierta dos lucernarios longitudinales orientados a Norte, uno para iluminar la zona de juego, y otro suplementario para el graderío alto. Venían, por tanto, impuestas las líneas de borde de estos lucernarios como elementos de paso de la cubierta. Estos lucernarios admitían una cierta inclinación sin dar paso al sol; inclinación que podría ser mayor si, como era prácticamente obligado, se cortaba la altura total de estos lucernarios con líneas horizontales, formando pequeñas viseras sobre cada plano de vidrios.

Así planteado el problema, se ocurría disponer unas cerchas transversales que, salvando esos lucernarios, permitieran el establecimiento de correas longitudinales, pero la forma que resultaba para esas cerchas era poco estructural y menos estética. Otra solución era utilizar los lucernarios como vigas longitudinales y establecer entre ellos una cubierta de directriz poligonal. Tampoco así la solución resultaba satisfactoria; el plano izquierdo quedaba con demasiada luz y requería vigas importantes.

Abandonando, pues, estas ideas, observando los puntos obligados por las necesidades de gálibo y de iluminación, y tratando siempre de buscar una línea envolvente que dejase diáfano todo el volumen de la sala, la mano traza instintivamente dos arcos, cuya simetría rima bien con la disimetría de toda la sala. La solución es posible a base de establecer una lámina cilindrica de dos lóbulos que, en las zonas de lucernarios, se convierte en una triangulación capaz de sostener los vidrios para dar paso a la luz

Evidentemente, este tipo de lámina de hormigón armado, en condiciones normales, resultaria demasiado costosa por la gran cantidad de madera de encofrado y de cimbra que requiere, al tener que hormigonarse de una vez-o, por lo menos, al no poder descimbrarse hasta que, en toda su superficie, el hormigón haya alcanzado la debida resistencia- . Sin embargo, en este caso especial, esto tenía poca importancia, porque la misma velocidad, a que se pedía la obra por razones financieras, anulaba todas las ventajas que, en este sentido, hubiese podido tener otra estructura formada por elementos capaces de hormigonarse y descimbrarse unos después de otros reutilizando los encofrados.

Por otra parte, el poco espesor, y consiguientemente poco peso de estas láminas, hace que la cimbra se reduzca prácticamente al andamiaje necesario, en todos los casos, para el trabajo de los obreros. Y, en fin, el constructor no tenía inconveniente en el empleo de más madera, que podía fácilmente reutilizar en otras obras ya comenzadas. 
exterior

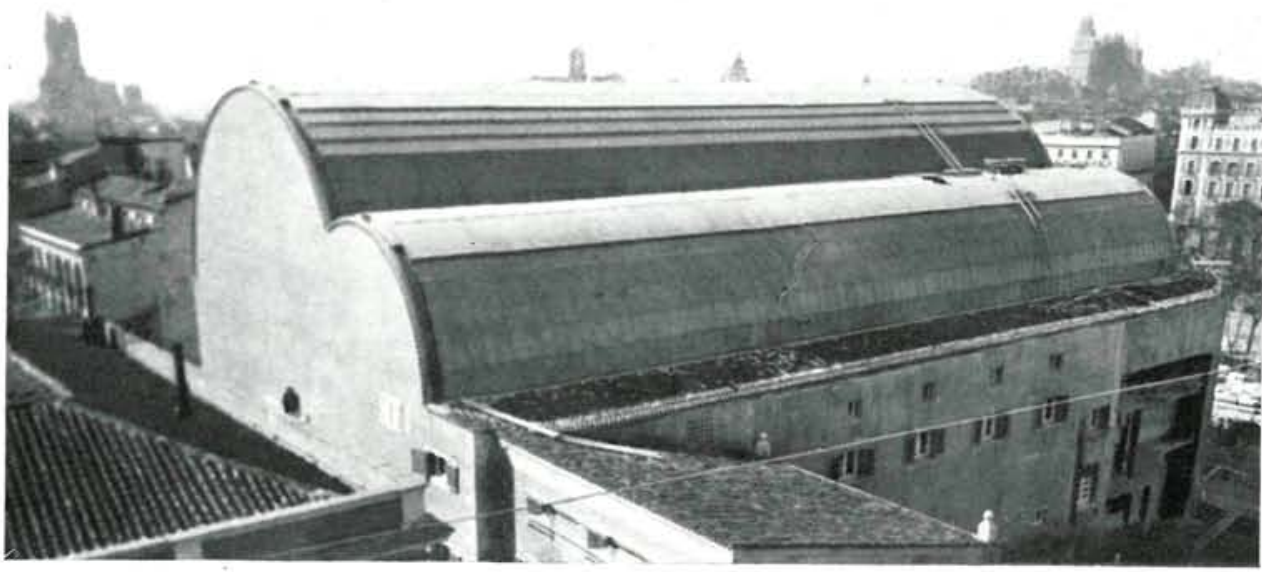

i n t e r i r

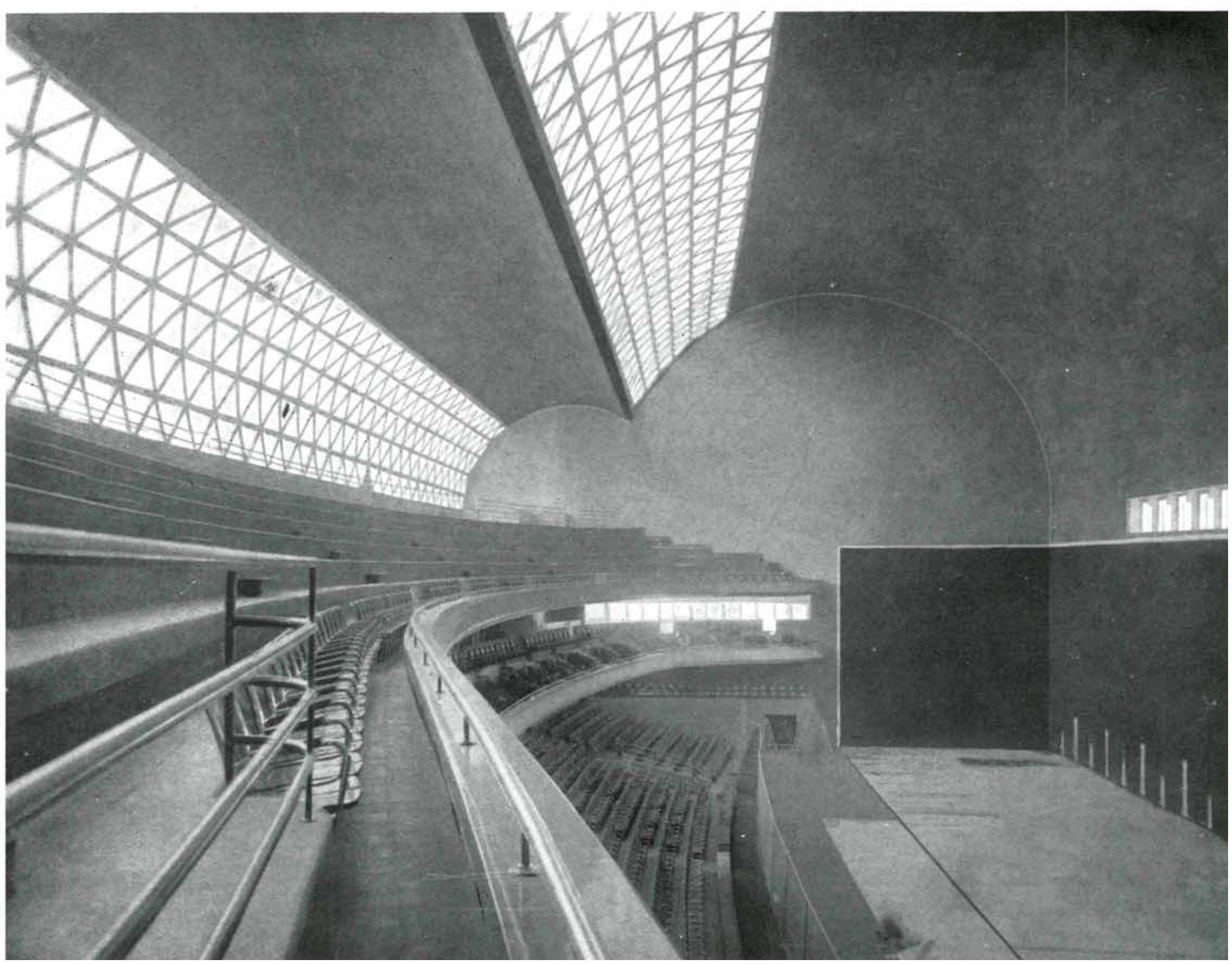


sección transwersal

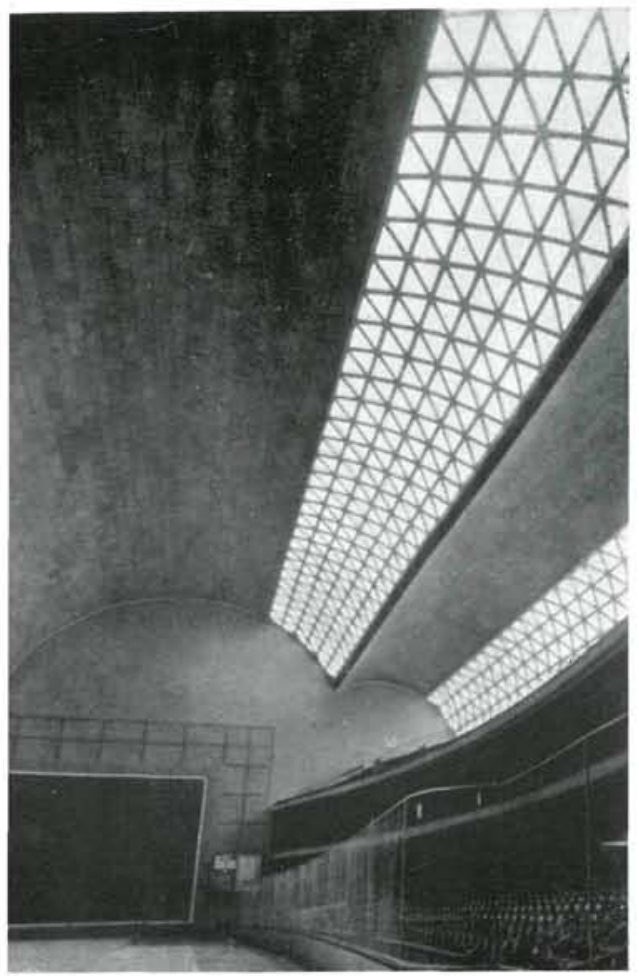

Por esta razón de velocidad, se fueron hormigonando las sucesivas plantas del edificio sin esperar a descimbrar las inferiores y se utilizó cemento aluminoso de rápido endurecimiento para el graderio superior y la cubierta. Gracias a todo ello fue posible completar la obra de excavación, cimentación y estructura total, incluso su descimbramiento en sólo noventa días de trabajo.

La cubierta puede definirse estructuralmente como una lámina cilíndrica de generatrices horizontales, de hormigón armado, con la directriz formada por dos arcos de círculo desiguales, que arrancando con tangentes verticales en los bordes se encuentran ortogonalmente, y en parte de los cuales se sustituye la lámina continua por celosias triangulares del mismo material.

p a m th
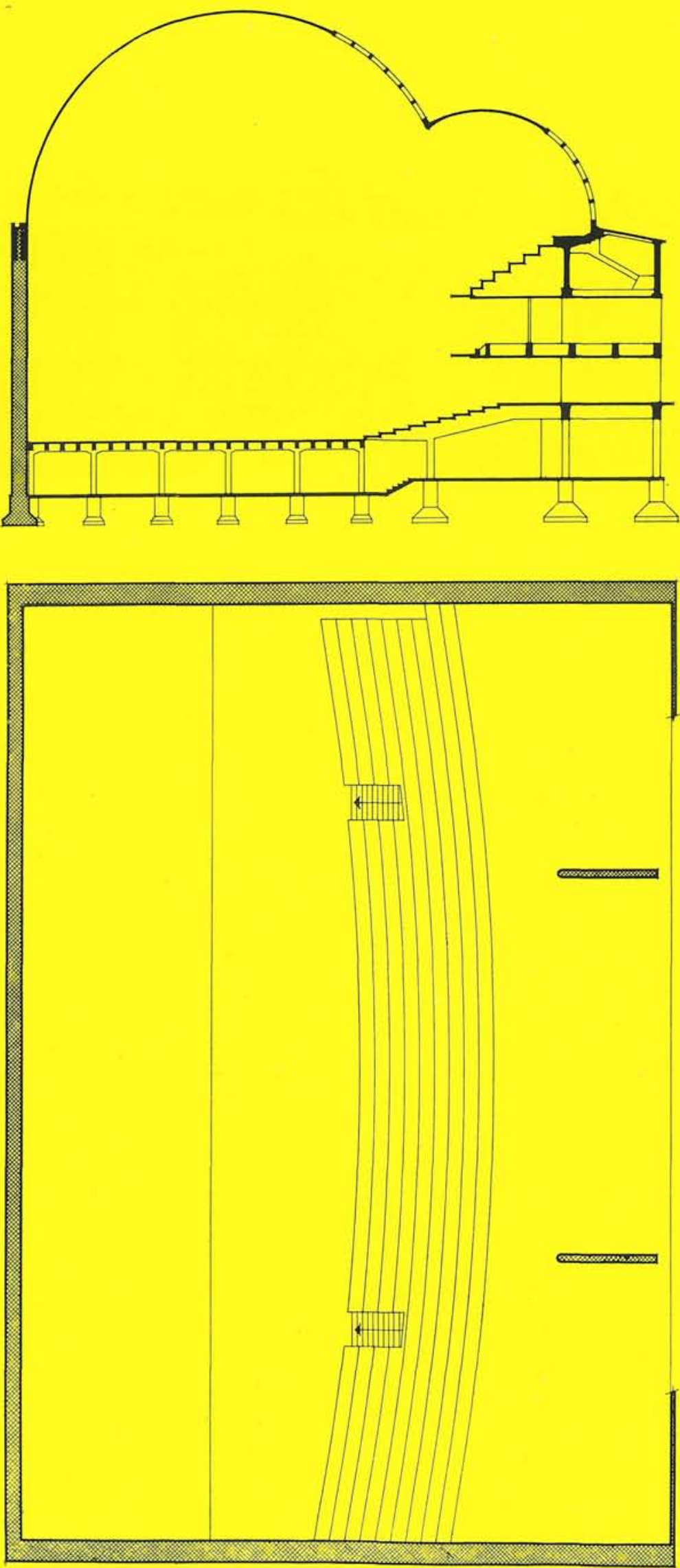

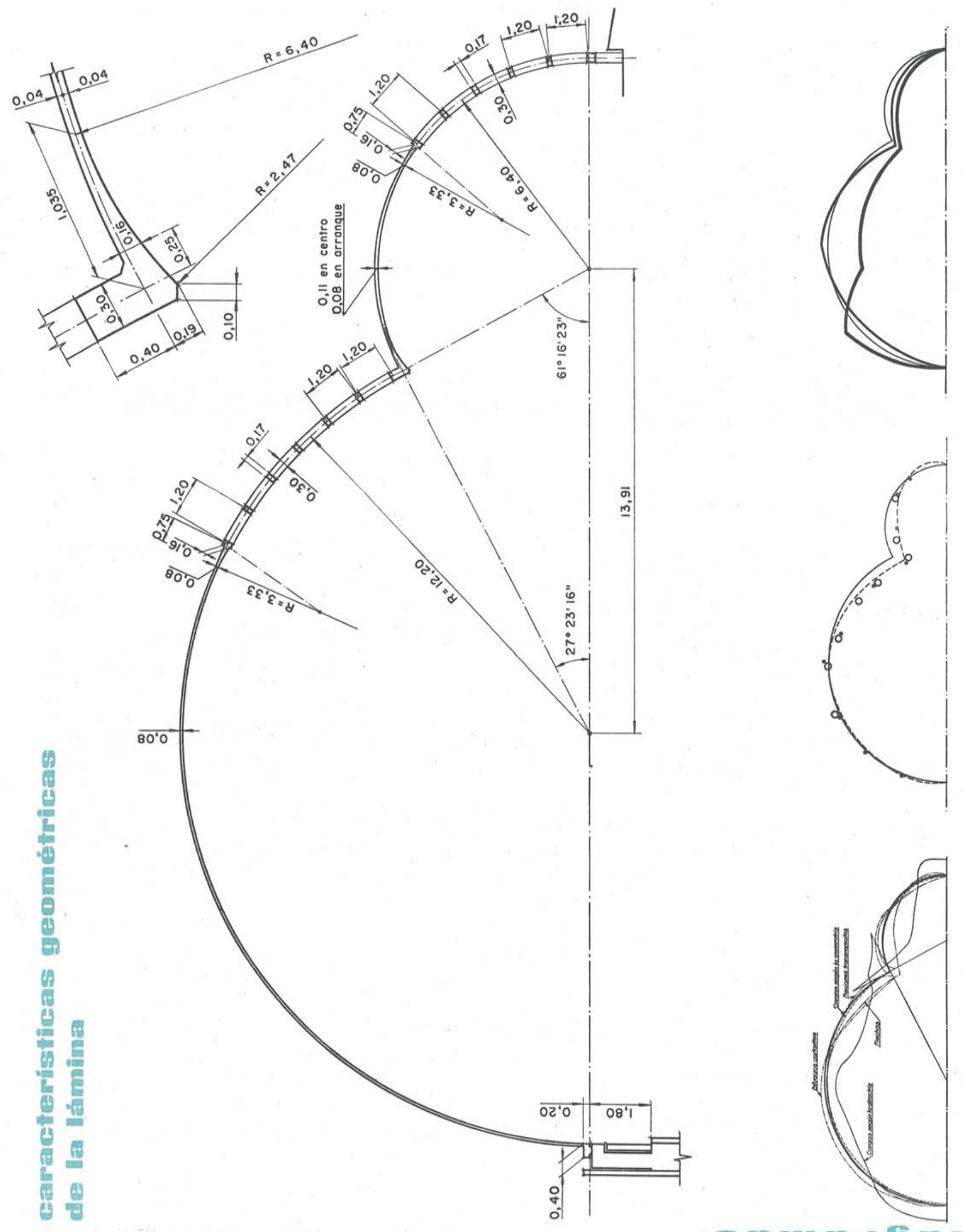

둥

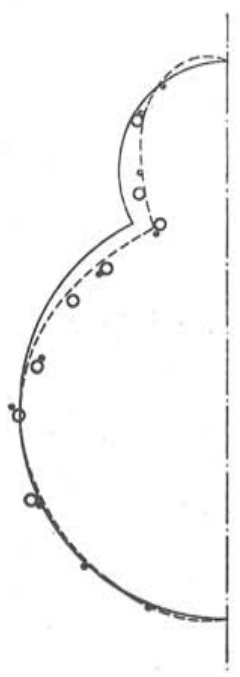

罚量

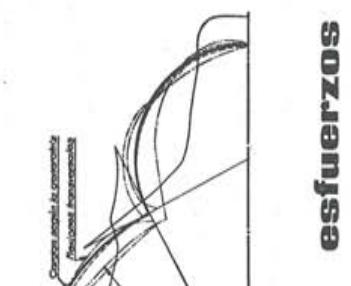

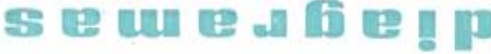




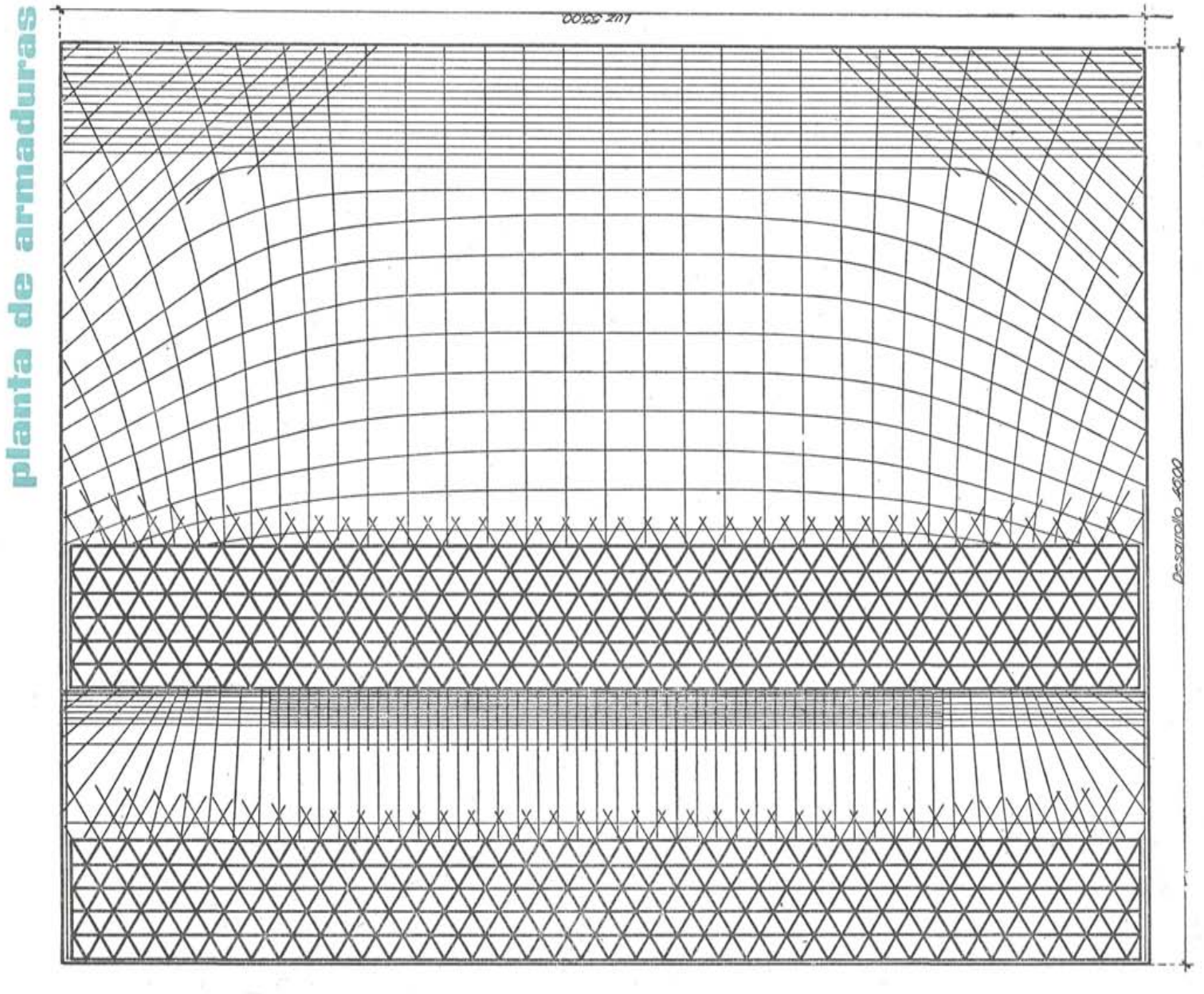

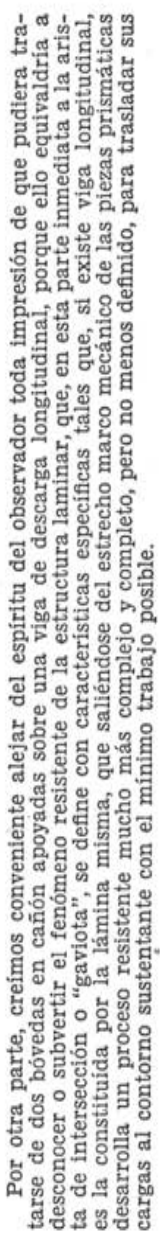
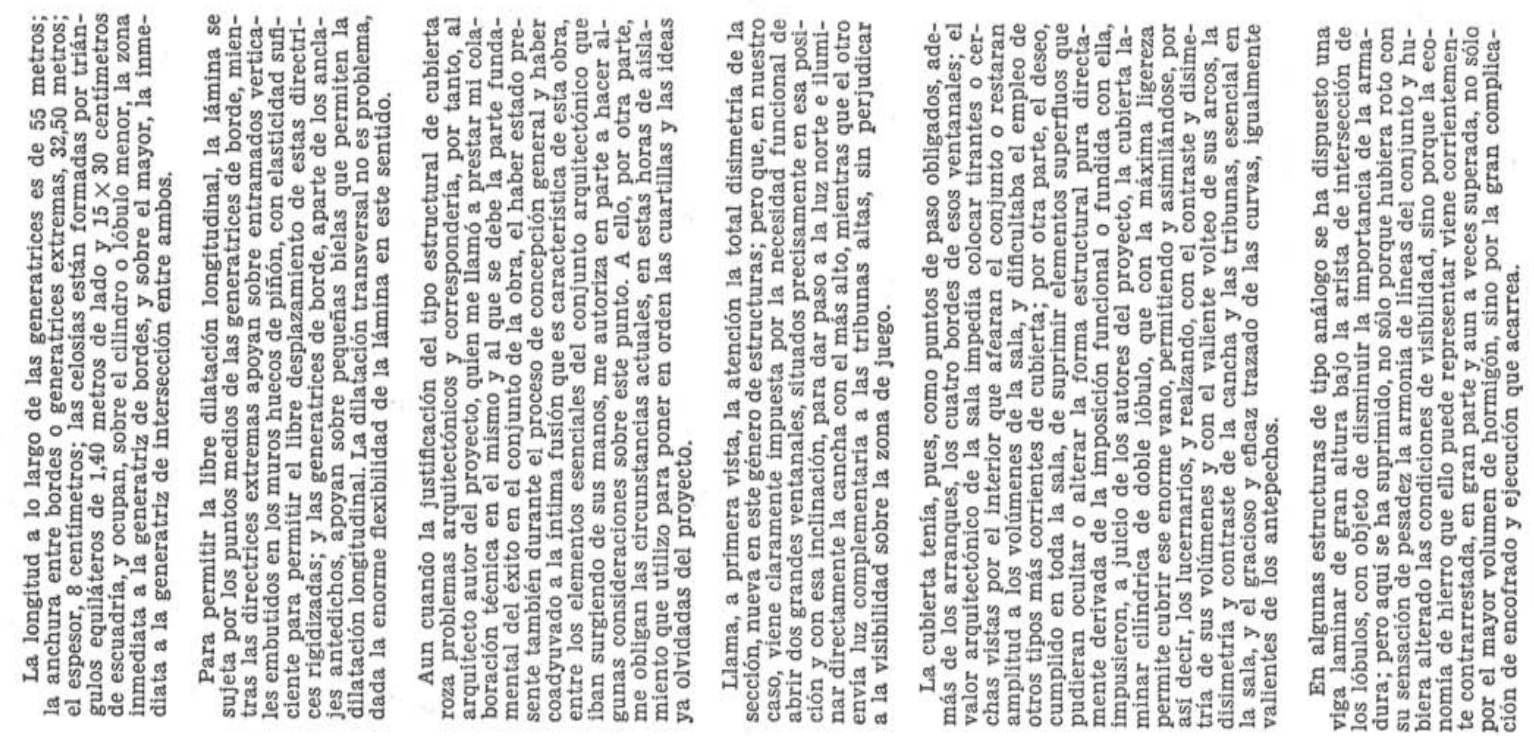


\section{ems a yo}

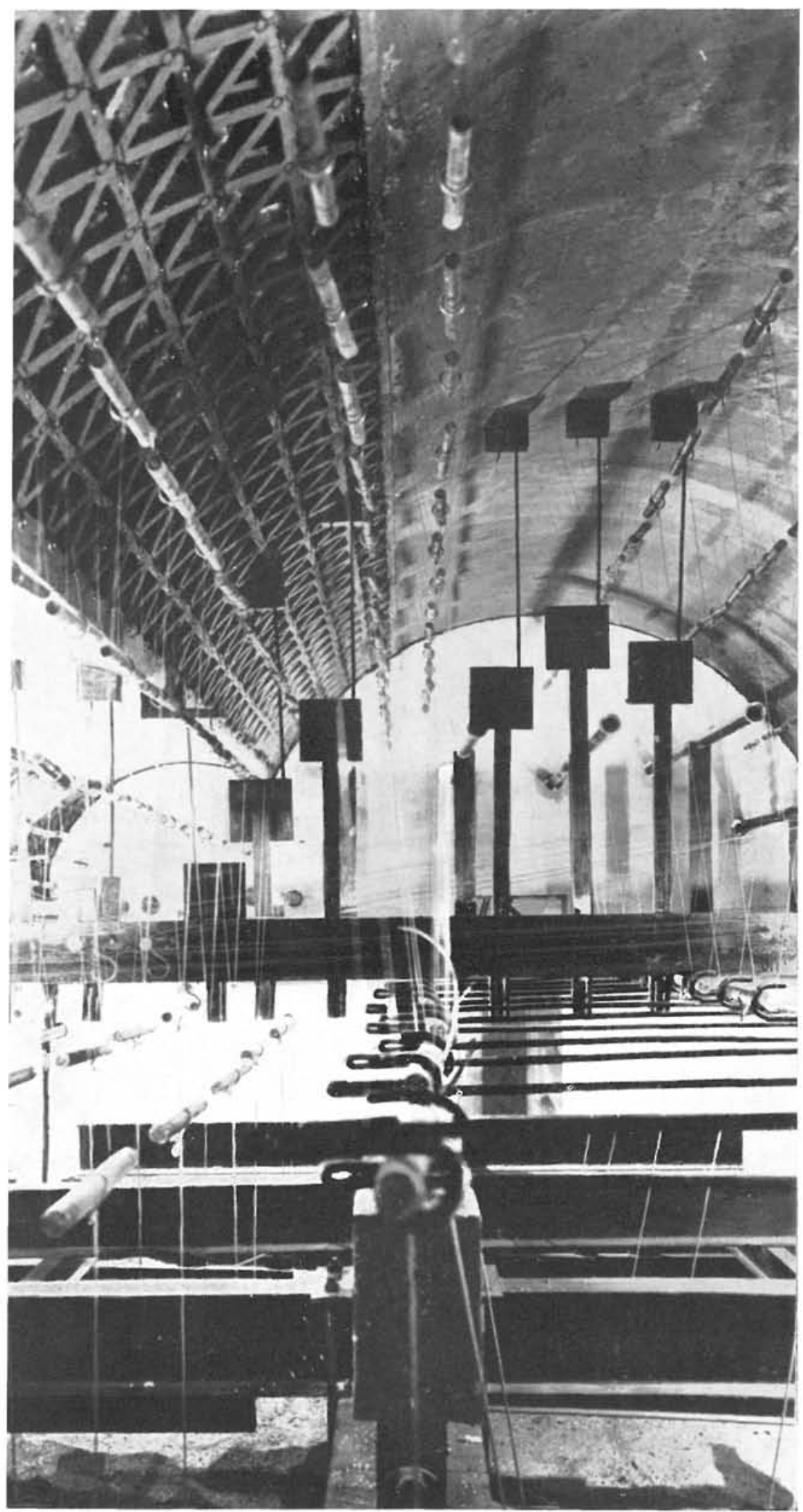

Por eso, sólo bien conocido este fenómeno resistente, que más adelante se desentraña analiticamente, se puede apreciar la limpieza y claridad de esta estructura con su contundente simplicidad de trabajo.

Un efecto análogo de economía de armadura se hubiera podido obtener, aunque en menor escala, haciendo más agudo el ángulo de la gaviota; pero ello hubiera favorecido la acumulación de nieve en ese punto, a no ser que se colocara por encima un tejadillo supletorio, enmascarando con ello en fachada las líneas estructurales de la cubierta propiamente dicha; y como en una obra arquitectónica de la importancia de ésta, no es la economía a ultranza la que ha de definir el trazado, y la diferencia de coste era muy pequeña, se consideró más conveniente el trazado elegido por satisfacer mejor al conjunto del problema.

No tiene, por otra parte, toda su justificación económica la cubierta laminar en este caso particular porque la disminución de materiales y mano de obra que lleva consigo ha quedado compensada por el gran coste del andamiaje, ya que la cubierta se hizo a toda cimbra; por eso es conveniente advertir que ni ello es hoy necesario en este tipo de cubierta, ni aquí vino impuesto solamente por consideraciones de orden técnico, sino por el buen aprovechamiento posterior, que podía hacerse de la madera $y$, sobre todo, porque desde un punto de vista financiero, el sobrecosto que la cimbra completa representaba quedaba más que de sobra compensado por los beneficios que reportaba el adelanto correspondiente en la terminación de la obra.

Es de destacar que la obra se llevó a una marcha tal, que la cubierta quedó totalmente descimbrada a las tres semanas de haber terminado el hormigonado de las tribunas inferiores y a los tres meses y medio de iniciarse los trabajos de cimentación del edificio, que tiene cinco plantas.

El cálculo de la lámina se hizo siguiendo el método propuesto y utilizado por Dischinger y Finsterwalder para estructuras análogas, como las cubiertas de Francfort y Budapest; si bien con algunas modificaciones y particularidades impuestas por la mayor importancia de ésta y por lo original y disimétrico de su perfil, pues los lóbulos de la cubierta de Budapest, por ejemplo (mayor que la de Francfort), tiene solamente 40 metros de longitud y 11,80 metros de separación entre bordes, con perfil simétrico, mientras que ésta tiene 55 metros de longitud y 23 metros de anchura entre bordes del lóbulo grande. 


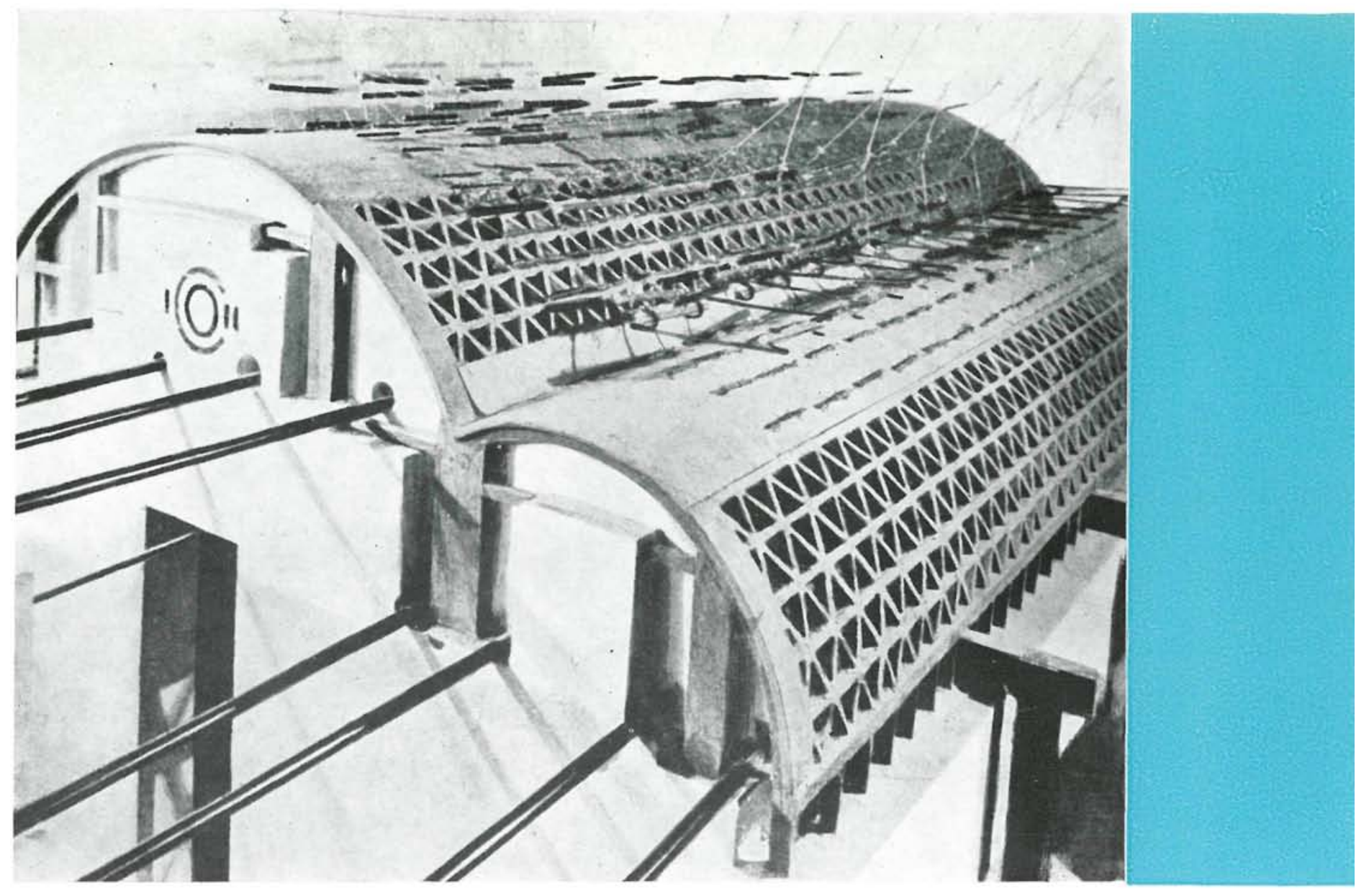

modelo reducido

Además, los lóbulos de Budapest enlazan con grandes vigas de descarga, mientras que aquí el enlace de los dos lóbulos se hace, como ya se ha dicho, en gaviota pura, sin viga de apoyo, y, sobre todo, el conjunto de la directriz tiene un peralte mucho mayor y ni puede, por consiguiente, prescindir del empuje del viento sobre la lámina, ni puede asimilarse la carga de nieve a la del peso muerto, y es necesario establecer leyes separadas para cada una de estas tres cargas exteriores.

Además, el suprimir la viga de descarga en la gaviota y adoptar el perfil impuesto por las necesidades funcionales y estéticas de la obra obliga a colocar un fuerte tirante o cordón a lo largo del vértice de la gaviota, el cual representa una parte importante del conjunto de armaduras de la cubierta. Así, pues, para no encarecer inútilmente la obra nos impusimos la condición de que la carga máxima de trabajo de esta armadura bajo la acción simultánea del peso del viento y la nieve fuera sensiblemente de $9 \mathrm{~kg} / \mathrm{mm}^{2}$, aun a trueque de la complicación de cálculo que ello representa.

Dada esta complicación y el peligro de errores que ello envuelve siempre, se completó el estudio con un ensayo experimental en modelo reducido; y se observaron cuidadosamente los corrimientos y deformaciones de toda la lámina tanto durante el descimbramiento como durante la primera época de vida de la obra. 

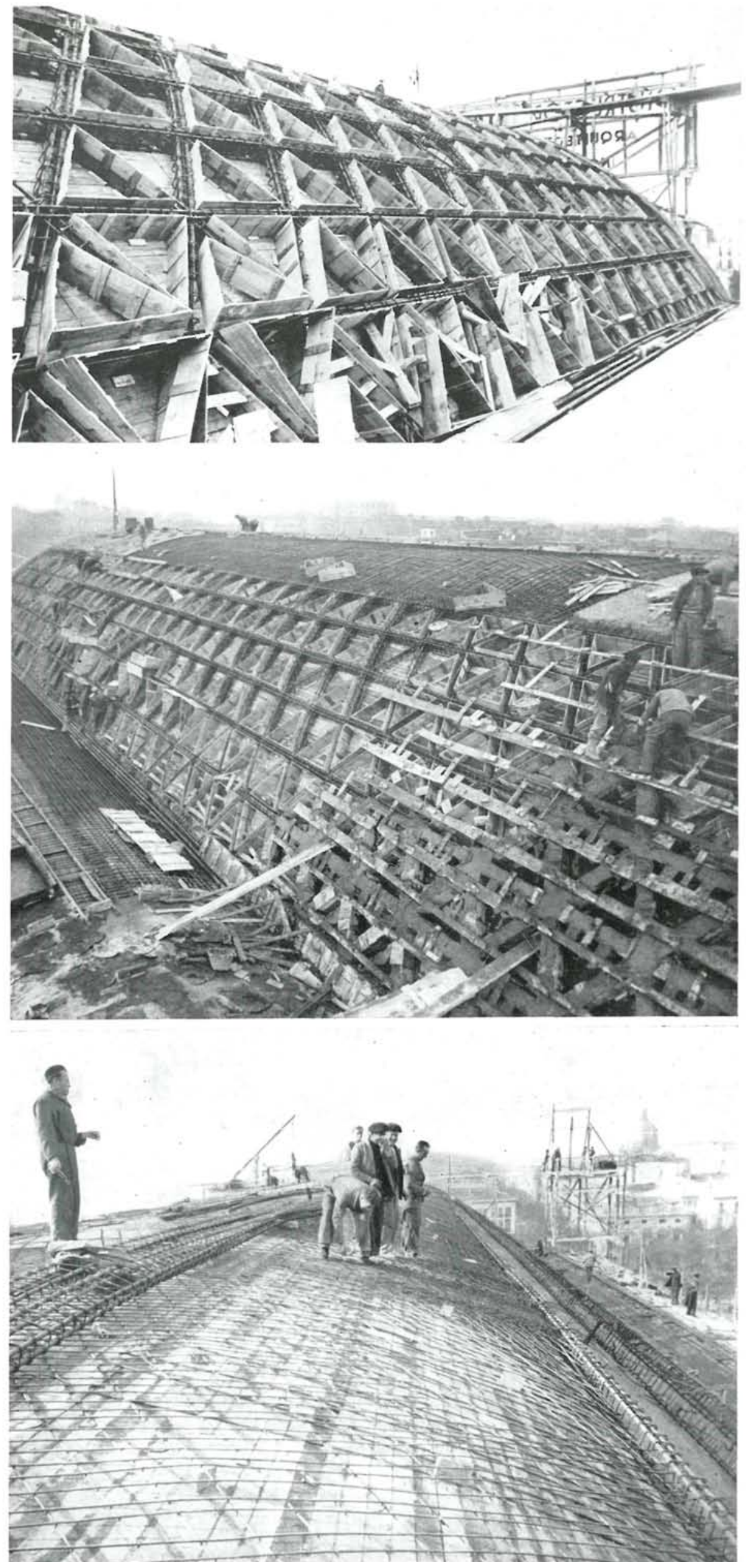

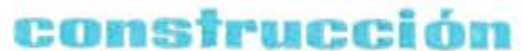

Los resultados de estas medidas coincidieron perfectamente con los del modelo, y ambos con los resultados del cálculo, salvo ligeras variaciones debidas a la mayor rigidez y algo mayor peso de los lucernarios respecto al resto de la lámina. Esto no había podido tenerse en cuenta en el cálculo dada la gran complicación que hubiera representado.

Esta estructura-la mayor del mundo en su clase-se terminó meses antes de estallar la guerra civil española. Durante ella sufrió varios impactos taladrantes, algunos de los cuales dejaron boquetes de varios metros cuadrados en la lámina. Sobre esto, los bombardeos de aviación debieron provocar fuertes oscilaciones, porque la arista quedó con más de $60 \mathrm{~cm}$ de flecha lateral, y la generatriz de clave estaba totalmente agrietada. En estas condiciones, las generatrices del lucernario alto, que trabajaban en compresion, quedaron curvadas y con fuerte tendencia al pandeo.

La imposibilidad, en aquellos momentos, de proceder a su reparación hizo que este pandeo fuera aumentando plásticamente hasta producir el hundimiento total. 

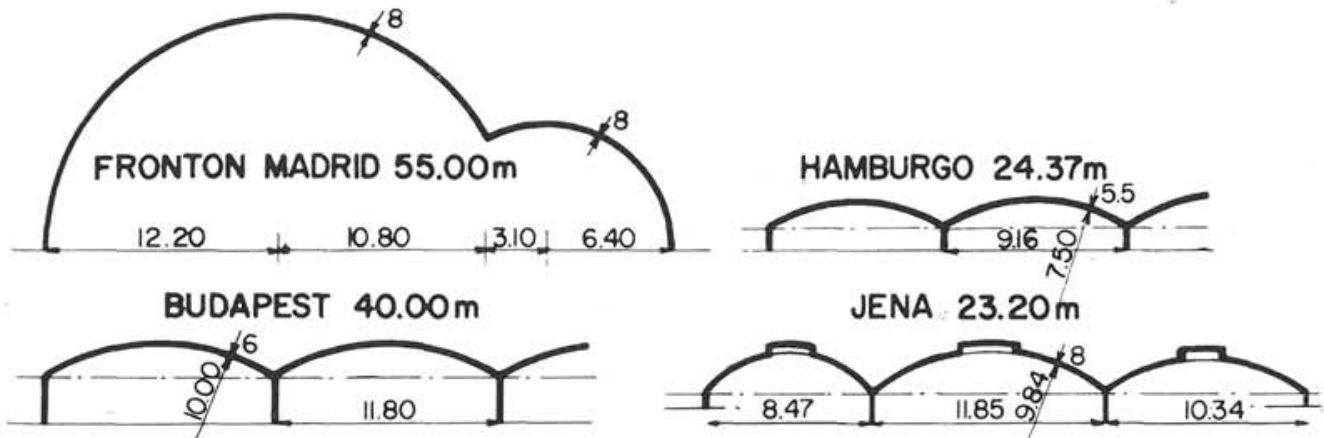

FRANKFURT. MERK. $36.90 \mathrm{~m}$

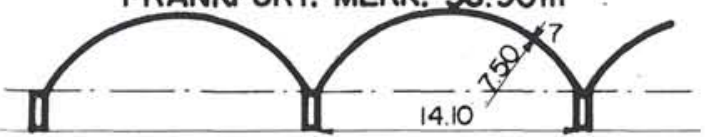

TURIN $23.10 \mathrm{~m}$

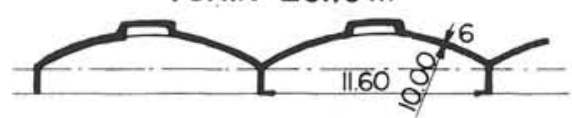

GREIZ $36.37 \mathrm{~m}$ ?

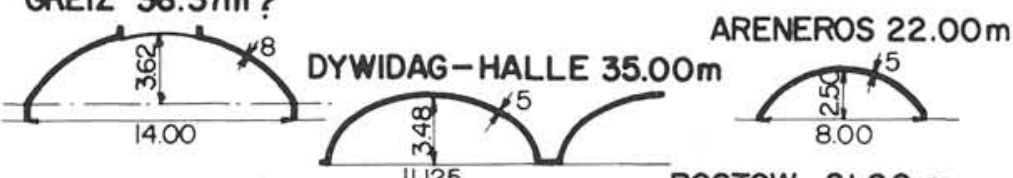

BRAILA $30.00 \mathrm{~m}$

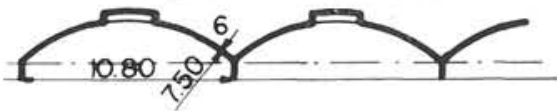

ROSTOW $21.00 \mathrm{~m}$

ROMA STA. $25.00 \mathrm{~m}$

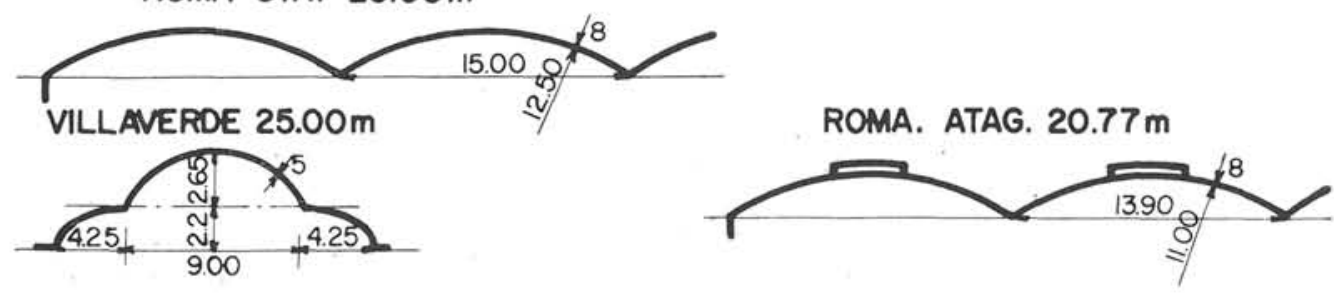

Seguramente, un rápido apeo y el establecimiento de unos anillos de refuerzo hubieran bastado para restablecer sus condiciones de trabajo.

Y seguramente también se habría evitado el hundimiento si se hubiera provisto de estos nervios a la lámina, desde el momento de su construcción. Colocados por la cara superior, no hubieran afectado ni al efecto estético ni al coste del conjunto. Indudablemente, si tuviese que repetirla hoy, lo hubiera hecho así; pero, desgraciadamente, ello serviría de poco frente a los tipos de bombardeo que cabe prever en el porvenir. 